\title{
Calcified Ventricular Aneurysm
}

\author{
Mohammed Alhasnawi \\ From the Department of Internal Medicine, Sultan Qaboos Hospital, Salalab, Sultanante of Oman. \\ Received: 27 Jun 2009 \\ Accepted: 03 Aug 2009 \\ Address correspondence and reprint requests to: Dr Mohammed Jawad, \\ Department of Internal Medicine, Sultan Qaboos Hospital, Salalab, Sultanante of Oman. \\ E-mail:mohammedalhesnawy@yahoo.com
}

Alhasnawi M. OMJ. 24, 303-305 (2009); doi:10.5001/omj.2009.62

T

eft ventricular aneurysm (LVA) is defined as a distinct area of abnormal left ventricular diastolic contour with systolic dyskinesia or paradoxical bulging. A False aneurysm is defined as a rapture of the left ventricular wall enclosed by a surrounding pericardium, with an incidence rate of $10-35 \%$ of developing a myocardial infarction, depending on methods used for diagnosis and definition. ${ }^{1,2}$

A 70 year old male patient was presented at Sultan Qaboos University Hospital in Salalah with a history of increasing shortness of breath and a cough producing a white coloured sputum over the last 2 weeks prior to admission. The patient also had a history of orthopnea and paroxysmal nocturnal dyspnea for the 2 days prior to admission. For two years prior to admission, the patient had experienced shortness of breath on performing ordinary activities, and swelling of both legs over the last 2 months. However, the patient had no chest pain, no palpitation, no dizziness, no chest pain on effort and no history of dysuria. The patient was known to suffer from Coronary Artery Disease and experienced a myocardial infarction (MI) 10 years back where a coronary artery bypass surgery (CABG) was performed. The patient also had a history of diabetes and hypertension but was on irregular treatment and irregular follow up.

On admission, the patient was dyspnoic, and his complexion had turned earthy in colour. The patient was also presented with bilateral leg oedema, raised JVP, his BP was 140/80, PR was 90 $\mathrm{B} / \mathrm{min}$, temp was normal at $37^{\circ} \mathrm{C}$, normal heart $\mathrm{S} 1, \mathrm{~S} 2$ and systolic murmur. Chest bilateral basal crepitation and abdomen palpable liver were also observed.

Investigations showed Serum creatinine was $369.8 \mathrm{mmol} / \mathrm{L}$, urea $32.47 \mathrm{mmol} / \mathrm{L}, \mathrm{K} 3.27 \mathrm{mmol} / \mathrm{L}, \mathrm{Na} 128 \mathrm{mmol} / \mathrm{L}$, Glucose $6.38 \mathrm{mmol} / \mathrm{L} \mathrm{Ca} 2.23 \mathrm{mmol} / \mathrm{L}, \mathrm{Ph} 1.1 \mathrm{mmol} / \mathrm{L} \mathrm{Hb} 13.4 \mathrm{~g} / \mathrm{dl}$, wbc 7.74, AST 60.8U/L, ALT 59.4U/L, bill 34.3 PT 22.8 seconds, INR 1.63. Urine exam revealed no glucose or protein in the sample, a white blood cell count of $<4$ cell in a $24 \mathrm{hr}$ collection of urine, $198 \mathrm{mg} / 24$ hours of protein and $0.117 \mathrm{ng} / \mathrm{ml}$ of Troponin

Chest $\mathrm{x}$-ray revealed a PA and left lateral cardiomegaly, calcified lesion on the left lower part of the chest and differential diagnosis for the calcified lesion was suggestive of either calcified ventricular aneurysm or a calcified thrombus, (Figure 1, 2).

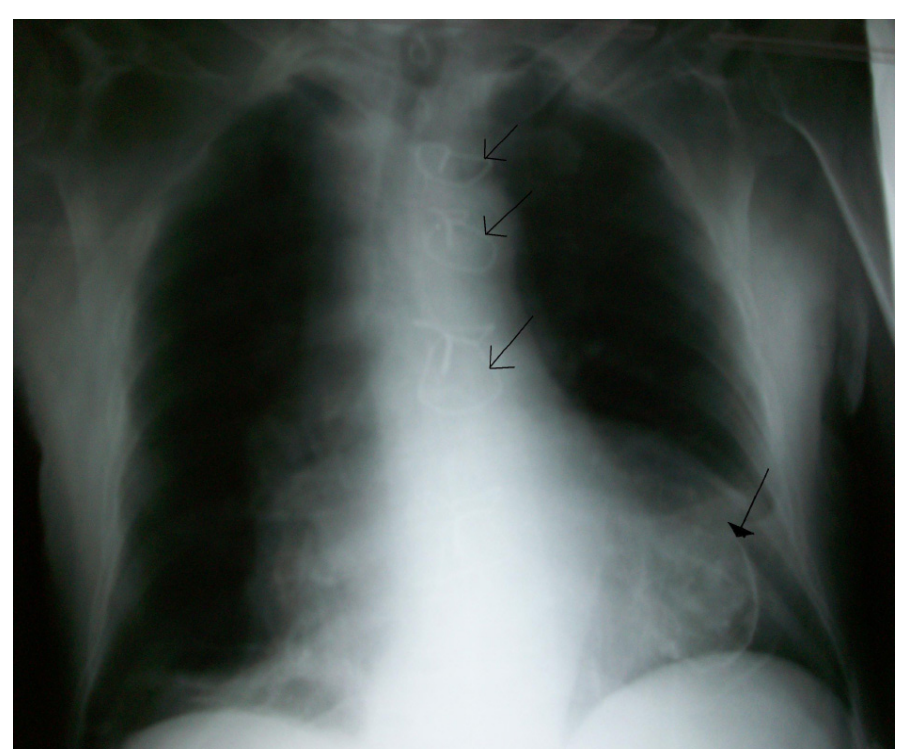

Figure 1: Chest X-ray

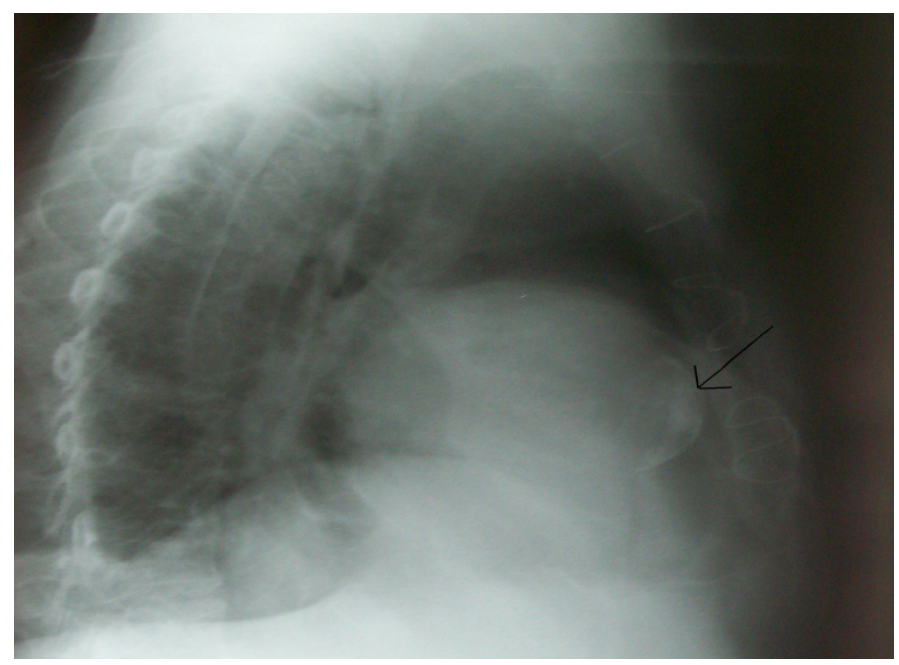

Figure 2: Calcified Lesion Found

Electrocadiography showed Sinus rhythm, conductive delay, Q wave II, III, AVF, V5-V6 leads, T-inversion I, and AVL. (Figure 3). Transthoracic echocardiography showed that all the cardiac chambers were dilated, calcified akinetic bulging of the apicoseptal area of the left ventricle, calcified mitral valve leaflets, calcified aortic cusps, moderate mitral regurgitation, mild aortic 


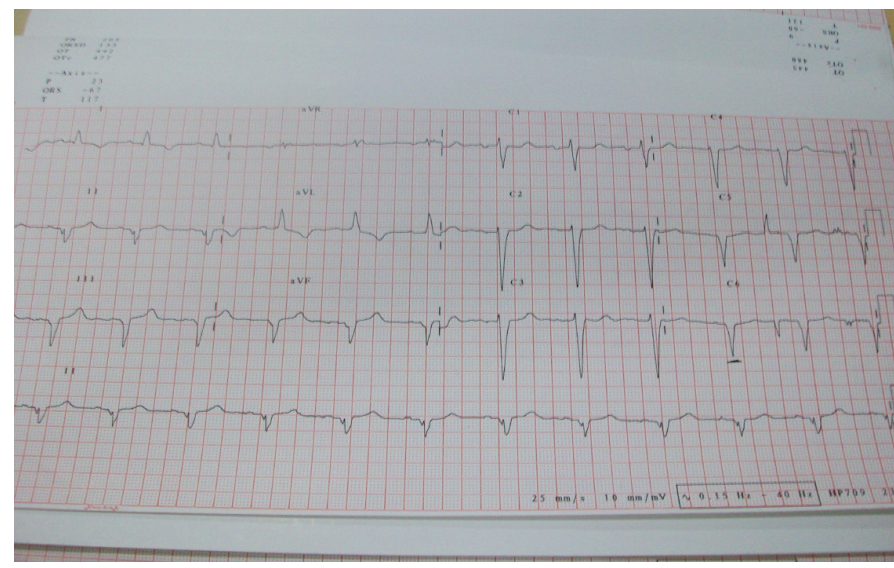

Figure 3: Electrocardiography

regurgitation, mild tricuspid regurgitation and left ventricular systolic dysfunction (EF 31\%). However, there was no thrombus, no pericardial effusion, and no vegetation, (Figure 4).

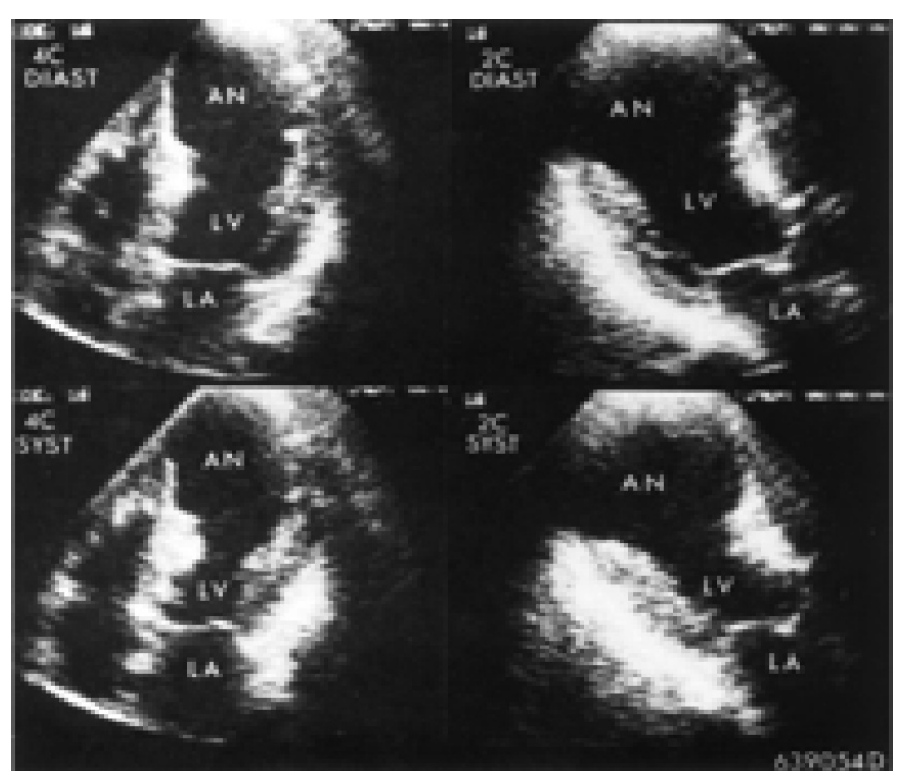

Figure 4: Transthoracic Echocardiography

CT-scan of the chest revealed calcified ventricular aneurysm, calcified aorta, and calcified left anterior of the descending artery (Figure 5).

The patient was admitted to the hospital and treated as a case of LV dysfunction and renal impairment.

Left ventricular aneurysm is a known complication of myocardial infarction with an incidence rate of $10-35 \%$, thus cases of calcified ventricular aneurysm are rare. $95 \%$ of ventricular aneurysm cases are caused by myocardial infarction, other causes include trauma, Chagas disease, sarcoidosis and very rarely,

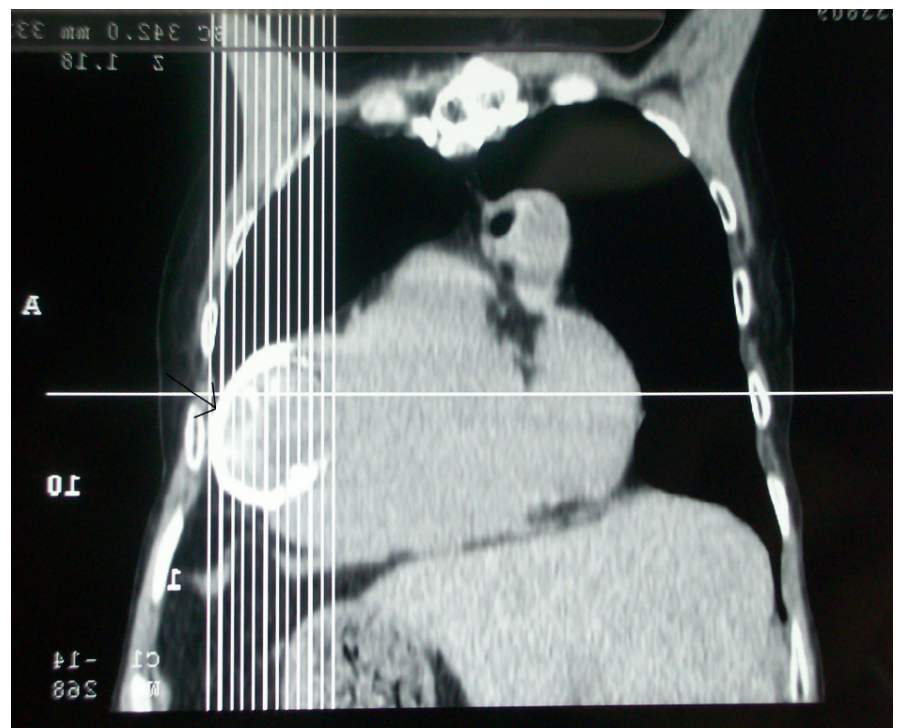

Figure 5: CT-can of the Chest

congenital LVA. Psudoanurysm may be caused by MI, after Mitral Valve Replacement or as a complication of septic pericarditis. ${ }^{3-7}$

Angina is presented in $60 \%$ of patients with 3 vessels disease. Dyspnea is usually presented due to systolic and diastolic dysfunction, while arterial and ventricular arrhythmias may present syncope, palpitation and sudden death. Thromboembolism is unusual; however, it may present a stroke, PVD or MI.

ECG usually shows $Q$ wave, persistent ST elevation indicative of the diagnosis, whereas Chest X-Ray cardiomegaly shows signs of heart failure, yet very rarely is it a sign of calcified aneurysm. However, chest X-Ray is not usually the diagnostic tool for LVA. $\mathrm{ECHO}$ is the golden standard test used for the diagnosis of LVA because it shows aneurysm size, valvular lesions and thrombus within aneurysm as well as systolic and diastolic functions. An MRI and MRA may also be used to diagnose ventricular aneurysm, while Ventriculography is rarely used; hence routine investigation with coronary angiography is a common procedure.

In the natural history of LVA, $90 \%$ of medically treated asymptomatic patients survive in ten years, while $46 \%$ of medically treated LVA patients were symptomatic patients.

The most common causes of death in LVA are arrhythmia which accounts for $44 \%$ of deaths, heart failure causes $33 \%$ of deaths, recurrent MI resulting in $11 \%$ and non-cardiac causes, accounting for $22 \%$ of deaths.

The factors which determine the survival of patients with LVA are; age, class of $\mathrm{HF}$, extent of CAD, duration of angina, prior infarction, $\mathrm{MR}$, ventricular arrhythmias, aneurysm size, function of residual myocardium, left ventricular and diastolic pressure (LVEDP), and early development of LVA.

The risk of thromboembolism is low $(0.35 \%$ per year) since 
long term anticoagulation is usually not indicated unless there is a history of thromboembolsim or AF. If a mural thrombus appears in echocardiography, the risk is increased to $19 \%$ per year and anticoagulation is indicated. Very rarely does rupture occur. ${ }^{8}$ Asymptomatic patients are medically managed.

Surgery is implicated in the presence of any of the following; recurrent angina, large aneurysm, congestive heart failure, rupture, psudoaneurysm, congenital aneurysm, recurrent embolism, CABG with significant aneurysm. ${ }^{9,10,11}$

Overall, LVA is a known complication of myocardial infarction. Calcified cases of LVA are rare. Calcified lesion within the heart shadow in chest $\mathrm{x}$-ray in a patient with a history of coronary artery disease may be due to calcified ventricular aneurysm or calcified thrombus and by evaluating echocardiography and CT scans, it is possible to differentiate between the two conditions.

\section{Acknowledgements}

The author reported no conflicy of interest and no funding was received on this work.

\section{References}

1. Therford JD, Braunwald E, Cohn PE. Chronic ischemic heart disease, in Braunwald E (ed): Heart Disease: A Textbook of Cardiovascular Medicine. Philadelphia, Saunders, 2005; 1364. Buckberg GD
2. Buckberg GD. Defining the relationship between akinesia and dyskinesia and the cause of left ventricular failure after anterior infarction and reversal of remodeling to restoration. J Thorac Cardiovasc Surg 1998 Jul;116(1):4749.

3. de Oliveira JA. Heart aneurysm in Chagas' disease. Rev Inst Med Trop Sao Paulo 1998 Sep-Oct; 40(5):301-307.

4. Silverman KJ, Hutchins GM, Bulkley BH. Cardiac sarcoid: a clinicopathologic study of 84 unselected patients with systemic sarcoidosis. Circulation 1978 Dec;58(6):1204-1211.

5. Davila JC, Enriquez F, Bergoglio S, Voci G, Wells CR. Congenital aneurysm of the left ventricle. Ann Thorac Surg 1965 Nov;1(6):697-710.

6. Antunes MJ. Submitral left ventricular aneurysms. Correction by a new transatrial approach. J Thorac Cardiovasc Surg 1987 Aug;94(2):241-245.

7. de Boer HD, Elzenga NJ, de Boer WJ, Meuzelaar JJ. Pseudoaneurysm of the left ventricle after isolated pericarditis and Staphylococcus aureus septicemia. Eur J Cardiothorac Surg 1999 Jan;15(1):97-99.

8. Grondin P, Kretz JG, Bical O, Donzeau-Gouge P, Petitclerc R, Campeau L. Natural history of saccular aneurysms of the left ventricle. J Thorac Cardiovasc Surg 1979 Jan;77(1):57-64.

9. Vlodaver Z, Coe JI, Edwards JE. True and false left ventricular aneurysms. Propensity for the altter to rupture. Circulation 1975 Mar;51(3):567-572.

10. Akins CW. Resection of left ventricular aneurysm during hypothermic fibrillatory arrest without aortic occlusion. J Thorac Cardiovasc Surg 1986 Apr;91(4):610-618.

11. Cherniavsky AM, Karaskov AM, Marchenko AV, Mikova NV. Preoperative modeling of an optimal left ventricle volume for surgical treatment of ventricular aneurysms. Eur J Cardiothorac Surg 2001 Oct;20(4):777-782. 